\title{
Study on China's Manufacturing Servitization Development Strategy
}

\author{
Zhu Gaofeng ${ }^{1}$, Tang Shoulian ${ }^{2}$, Hui Ming ${ }^{3}$, Li Yan $^{4}$, Tang Yiwei $^{5}$ \\ 1. Ministry of Industry and Information Technology of the People's Republic of China, Beijing 100804, China \\ 2. School of Economics and Management, Beijing University of Posts and Telecommunications, Beijing 100876, China \\ 3. China Machinery Industry Federation, Beijing 100823, China \\ 4. China Center for Information Industry Development, Beijing 100846, China \\ 5. Research Center for Development Strategy, Beijing University of Posts and Telecommunications, Beijing 100876, China
}

\begin{abstract}
This study is based on the research report titled "Manufacturing Servitization Development Strategy," which is a subproject of a major advisory project organized by the Chinese Academy of Engineering: The Manufacturing Power Strategy II. The servitization strategy of China's manufacturing industry is discussed, including the necessity of its implementation, implications of servitization, service mode, management mode, and related modern information technology and service platforms. The core of manufacturing servitization is still manufacturing; however, the manufacturing industry can expand its development space and enhance its competitiveness through servitization. Customer-oriented manufacturing enterprises offer a wide range of services, including product customization, leasing, financing, monitoring, e-commerce, supply chains, project contracting, and recycling services; in this way, they represent a new type of industry that is characterized by the integration of products and services. Manufacturing servitization shows two converging trends. The first trend is close cooperation and integration between the manufacturing industry and producer services. The second trend is the integration of the manufacturing industry with modern information technology. Manufacturing enterprises are building product design service platforms, e-commerce service platforms, remote-monitoring service platforms, and supply chain service platforms that are based on the Internet.
\end{abstract}

Key words: manufacturing servitization; service-oriented manufacturing; development strategy

\section{Service is one of the strategies of manufacturing power}

Since the reform and opening-up policy, China's manufacturing industry has been developing rapidly, and China has become a global manufacturing power. One important reason is the demographic dividend brought by inexpensive labor. However, China's population has begun to age. The labor supply is tightening, and labor costs are rising. The second reason is that, because the industry employment population has been decreasing since 2013, some manufacturing enterprises have begun to move out or use robots and other automation devices.

The development of the manufacturing industry also makes the market for the manufacturing products of the country show the obvious characteristics of a buyer's market even the phenomenon of overcapacity. Iron and steel, coal, oil, building materials, the petrochemical industry, and so on, which have long been key to the rapid growth of the national economy, have experienced serious overcapacity and an economic downturn. In the market, advanced technology, good quality, and good service are becoming more important.

Over the years, China's manufacturing industry depended

Received date: April 25, 2017; Revised date: May 18, 2017

Corresponding author: Tang Shoulian, School of Economics and Management, Beijing University of Posts and Telecommunications, Professor, PhD Supervisor. Major research field is management science and engineering. E-mail: tangshoulian@263.net

Funding program: CAE Advisory Project "Research on Manufacturing Power Strategy (Phase II)" (2015-ZD-15).

Chinese version: Strategic Study of CAE 2017, 19 (3): 089-094

Cited item: Zhu Gaofeng et al. Study on China's Manufacturing Servitization Development Strategy. Strategic Study of CAE, https://doi.org/10.15302/ J-SSCAE-2017.03.013 
on the resource-type growth, following the development idea of treatment after pollution, showing the industrial characteristics of high input, high consumption, high pollution, low quality, and low efficiency. This approach resulted in serious environmental pollution and increasing consumption, weakening the manufacturing industry's sustainable development.

After the international financial crisis in 2008, the developed countries put forward a development strategy of revitalizing the manufacturing industry, and they implemented trade protectionism, causing trade friction and limiting the export of China's manufacturing products. India, Vietnam, and other developing countries, in the time of "demographic dividend" weakening, encouraged the transfer of global labor-intensive manufacturing with lower labor costs so that manufacturing enterprises moved out of China. China's manufacturing industry faces a severe situation involving attacks from both sides.

Facing the grim situation of the labor market, product market, natural environment, and industrial layout, China's manufacturing industry urgently needs strategic transformation, looking for a new development direction and new profit space. In the firstphase study of the "manufacturing power" project of the Chinese Academy of Engineering, the strategy of "four modernizations" from "big to strong" and "strong manufacturing power" is put forward, based on quality, intelligence, service, and green manufacturing. For China's manufacturing industry, building an international brand requires quality, enhancing the technology level requires intelligence, maintaining development space requires green policies, and expanding and upgrading industrial value require service.

Although some leading enterprises and featured enterprises in China's manufacturing industry have initially achieved success in service transformation, most enterprises are still in the stage of basic service, or they even lack a service development plan. Compared with the advanced international level, there is still a big gap between that level and the level found in the service-oriented manufacturing industry in China.

\section{Connotation of "service-oriented manufacturing industry"}

The service transformation of the manufacturing industry is not a hollowing of the manufacturing industry, nor is it the transformation of manufacturing enterprises from the production of tangible products into service enterprises that provide intangible services. The core of manufacturing servitization is still manufacturing, including both manufacturing-based services and service-oriented manufacturing. The expression "manufacturing servitization" includes business-to-business services for downstream businesses and business-to-consumer services for end users. Examples of the former are service outsourcing and package solutions; examples of the latter are diversification and differentiation customization, as well as design that allows customers to participate in the whole process. The forms of organization include expansion by manufacturing enterprises of the service areas, such as, in the United States, the direct sales of Dell and IBM's solutions, as well as service enterprises penetrating the manufacturing field, such as Wal-Mart in the area of manufacturing control, and the cross fusion and mutual penetration of manufacturing enterprises and service enterprises. In terms of attributes, services of the manufacturing industry show three characteristics: integration, added value, and innovation. Integration refers to the closer ties between enterprises. They share resources and serve each other to achieve the optimal dynamic distribution of resources among enterprises. Added value means to gain additional value and increase profits through service. Innovation refers to the provision of new tangible and intangible products by the integration of distributed knowledge resources and customer demand information through services, to improve the overall innovation ability of enterprises.

The production link mainly depends on the basic elements of production - that is, the direct manufacturing links of raw materials, energy, labor, and capital. R\&D design and after-sales service depend more on the growth of human capital and the explicit or tacit knowledge of science and technology. They are the indirect manufacturing links based on advanced production factors, and they show the additional value that is far higher than the production link. Under the pressure of severe market competition, the profit space of direct production is getting smaller. Manufacturing enterprises are increasingly extending into R\&D design and after-sales service, pursuing new profits and developing new sources of income.

The manufacturing industry in Europe and the United States has used its advantages to deepen international industrial division and control R\&D and sales services, which always occupy the commanding heights and high profits of the world's manufacturing industry. In China's manufacturing industry, several typical service enterprises are emerging.

Service is the rational choice for manufacturing enterprises to enhance their own competitiveness. It is an effective way to develop the manufacturing industry and promote value. In the process of service transformation, manufacturing enterprises change from producing only physical products to providing comprehensive products that can meet the needs more, from only producing profits to obtaining higher service benefits. The manufacturing sector also includes the productive services sector. Manufacturing servitization is a dynamic process of development and evolution of the integration of manufacturing and service. The service portion of the manufacturing industry shows obvious new industrial characteristics, such as the integration of products and services, the maximization of profits by ensuring maximal customer satisfaction, the networking driven by information technology, and the industrial chain gathered by upstream and downstream enterprises.

Service-oriented manufacturing requires enterprises to 
provide customers with better and better service contents, but few enterprises can independently complete these services. Therefore, many enterprises need to aggregate to form service networks to achieve division, cooperation, and complementary advantages. This service network of suppliers, manufacturers, service providers, distributors, and customers extends beyond traditional business relations in new-product development, production planning, quality assurance, equipment management, inventory management, infrastructure construction, customer service, product lifecycle management, and other areas to achieve closer coordination and cooperation.

\section{Service model of manufacturing industry}

The traditional manufacturing industry respected "product-oriented," "production as the core," and "sell as the end" principles, pursuing the low cost and production profit of mass production. Service-oriented manufacturing respects "customer-oriented" service as the "core" and "covering the whole life cycle of the products," with more emphasis on services, satisfying customer diversification and differentiation needs, and obtaining service income; thus, its business model and that of the traditional manufacturing industry are essentially different - that is, more open and active in terms of the types of services and service mode of diversification.

What services and what kind of service mode should be used in different manufacturing industries depend on the product itself and its industry characteristics, on the type of service, and on the service provider, relying on different means, depending on the service characteristics of the object and purpose of the service. The equipment manufacturing industry mainly sells production equipment and raw materials to other enterprises. Therefore, it is more important to integrate into other enterprises' production processes and provide more-effective services, such as financial leasing, remote monitoring, real-time maintenance, and engineering contracting. Light industry and the textile industry are mainly for family or individual consumers, so they need to provide more-diversified customized services and more-convenient sales and distribution services.

\subsection{Production and consumption custom service}

Custom service includes not only the consumer customization service for the end consumer but also the production customization service for the downstream enterprises of the industrial chain.

Production customization services can be divided into three levels: new-technology R\&D customization, new-product design customization, and new-product style customization. In accordance with the requirements of the downstream enterprises, manufacturing enterprises carry out the corresponding technical $\mathrm{R} \& \mathrm{D}$ and product design, and they produce new technology and products. Through customized services, enterprises can fill in the blanks of manufacturing technology and products, expand the market space of enterprises, and lay the foundation for the whole manufacturing industry. The essence of production customization services is innovation, which is more important than for consumer custom services.

The iron and steel industry in China carries out deep processing services for downstream enterprises, including material, marketing and industrial deep processing. For example, Baosteel Group implements steel extension processing, such as steel structures, metal packaging, and auto parts. Although this kind of processing is relatively simple, it belongs to production customization service.

Light industry, according to the needs of consumers, such as customized furniture, kitchen hardware, and lighting, as well as high-end customized bags, glasses, musical instruments, and other products according to the needs of specific consumers, all belong to consumer custom service. For example, the Haier Group, using an Internet customization platform, has implemented module customization, customization initiated by end users, and exclusive customization business.

\subsection{Leasing and financing services}

Leasing or financial leasing services are mainly used in the equipment manufacturing industry, such as automobile manufacturing, aviation manufacturing, general equipment and special equipment manufacturing, electrical machinery and equipment manufacturing, computers, communications, and other electronic equipment manufacturing industries.

The customer can lease the equipment and its related services. In this way, the investment of equipment can be saved effectively, and the equipment renewal and technical transformation can be realized in time.

Aero engine manufacturer Rolls Royce launched the "rent business hours" mode. General Electric in the United States established a financial services company to carry out financial-leasing services. China's Zoomlion Heavy Industry Science \& Technology Co. Ltd., Xugong Group, SANY Heavy Industry Co., Ltd., Guangxi Liugong Machinery Co., Ltd. and other enterprises have also carried out financial-leasing-related services.

\subsection{Intelligent-monitoring service}

To improve and guarantee the quality of the use of the product, manufacturing enterprises use information technology and intelligent technology, including sensor technology, noncontact detection technologies, and remote information transmission technology, to establish remote-monitoring centers, remote-diagnostic centers, and uninterrupted-response centers through intelligent support systems to realize the trend of remote fault diagnosis, the performance of product inspection, run fluctuation, 
etc. This service is mainly concentrated in automotive, home appliance, elevator, medical equipment, mechanical equipment, electrical equipment, environmental protection equipment, robotics, aerospace equipment, and navigation equipment manufacturing, as well as the current emerging intelligent household and personal-wear-type medical testing equipment remote-monitoring services.

China's Xi'an Shaangu Power Co., Ltd., Qingdao Jieneng Steam Turbine Group, Guangxi Liugong Group, Shaanxi Automobile Group, and XJ Schindler (Xuchang) Elevator Co., Ltd. are all trying to provide this service. Rolls Royce also conducts full-time testing services while leasing products.

\subsection{Business and supply chain services}

To expand the industrial added value and profit space and to enhance the market competitiveness of enterprises, more countries and regions are setting up trade services areas. Many manufacturing enterprises are also providing upstream and downstream enterprises and customers with business services, constantly enhancing the levels of business service and supply chain service.

Manufacturing enterprises, through establishing a business service system connecting supply, production, and sale with customers, integrate resources from sellers, buyers, and related service institutions, such as financial institutions, banks, insurance companies, business management departments, law firms, advertising companies, and logistics enterprises. And the manufacturing enterprises establish business flow, information flow, cash flow, and logistics systems of synergy to expand signing, execution, and legal protection of business contracts, and to optimize inventory management and logistics services.

\subsection{Project contracting service}

To better guarantee and improve the use efficiency of products in the whole life cycle, especially the mechanical equipment used in production, manufacturing enterprises provide relevant technical integration and engineering contracting services. These services include the provision of complete sets of equipment, automated production lines, whole workshops, the overall solution of the whole plant, and related consultancy and financing services, to provide design, procurement, construction, and commissioning, as well as infrastructure construction, workshop and peripheral facilities engineering, general contracting, and "turnkey" services. This is done to overcome mutual restriction or disconnect problems during design, procurement, and construction and to shorten the construction period, improve the quality of projects, and reduce the project cost.

Xi'an Shaangu Power Co., Ltd. has changed from being a single-product to a system solution and system service provider.
Shanghai Electric Group actively expands the general contracting service of power station projects.

\subsection{Recycling services}

Modern manufacturing enterprises carry out product recycling and remanufacturing services, turning waste into a resource and opening up new revenue sources for enterprises. This service model mainly applies to the recycling of value and the recycling of environmentally friendly products, such as used cars and their parts, engineering machinery, machine tools, and electronic products.

In 2005, the state council issued a document entitled "Opinions on Accelerating the Development of Circular Economy," which explicitly supported the development of remanufacturing industries. Weichai Power set up an engine and engine parts remanufacturing company in 2008. Worldwide Automatic Transmission Co., Ltd. has been making automatic transmissions of various types of cars for many years.

\section{Business model of manufacturing servitization}

The production and services of manufacturing enterprises can be divided into four relations. One is separation of products and services. Manufacturers provide products that do not provide services. The second is product add-ons. Service, as the product's appended content, does not produce independent commercial value. Third is the product-plus-service package. Services begin to become an integral part of the product and become part of the product's value. Fourth is service additional products. The product becomes a part of the service, and the value is mainly reflected in the service. These four relationships correspond to four business models of manufacturing enterprises, focusing on production, proprietary services, outsourcing services, and focus services.

The first type of manufacturing enterprise focuses on production and manufacturing, and the enterprises receive a large amount of other enterprises' entrusted agent production to achieve scale, reduce costs, and improve production efficiency. Such enterprises do not provide services, but they entrust other independent enterprises to provide services separately.

The second type of manufacturing enterprise uses its own services to provide relevant services. The advantages are professional and economical transaction cost, but this type of enterprise requires higher professional skills and a larger service scale.

The third class of manufacturing company services business delegates or outsources to other service companies, despite the need to pay the transaction cost, but can focus on its core work and cultivate the core competitiveness. At the same time, through more-professional and more-low-cost outsourcing services, it can improve customer satisfaction. 
The opposite of focused production is focused service. Some manufacturers simply outsource production to other companies. They focus on the R\&D of design work and after-sales service to highlight the technical advantages, seize the high end of the industrial chain, and establish the image of a high-tech and service brand.

IBM has eliminated its hard disk, PC, printer, X86 server, chip, and other hardware manufacturing, retaining only the large servers, supercomputers, professional graphics workstations, and a small amount of storage devices, such as physical production. Instead, it is moving toward IT technology solutions, software services, and services for the Internet of Things, such as large data cloud service platforms for overall solutions, creating a strategic layout.

Under the influence of these four modes of operation, a thirdparty professional service enterprise is gradually developed. Gradually, producer services are formed.

From the perspective of historical development, after industrialization, developed countries have slowed down manufacturing, while services have accelerated. Manufacturing and services are zero-sum or win-win, becoming an important issue. At present, China is also starting to have this problem, but the trend of manufacturing servitization is making possible the integration of the two, which can solve the problem better through integration.

With the transformation of manufacturing enterprises and the development of producer services, manufacturing and producer services have begun to cooperate even more closely. Their mutual influence, interaction, and common development have formed a positive interaction and complementary relationship, effectively promoting the common development of these two industries.

\section{Service information technology and service platform}

Modern information technology is the basis of manufacturing services. It can provide services across time and space constraints. It can realize remote-trading products and the production and service implementation of remote sensing, control, and data storage. It can analyze information and realize the standardization of services and intelligence, Specifically, it can be divided into three categories - modern communication technology, advanced computing technology, and ubiquitous sensing technology - as well as their mutual integration and network coordination.

Modern communication technology mainly refers to broadband communication technology, wireless data communication technology, mobile communication technology (such as telecom network transmission technology), near-field communication technology, communication technology and infrared sensor networks, real-time and reliable data collection, storage, low-delay transmission technology, big data, and cloudcomputing communication technology.

Advanced computing technology refers to a technology system that can collect, store, process, simulate, and display multimedia based on a computer and its network. These technologies include database; knowledge base; model base; data warehouse; data storage; cloud storage; data analysis; data mining; data analysis; cloud computing; computer modeling; simulation and numerical simulation; modular design and platform design; virtual design and computer-aided intelligent design; cognitive recognition of customers; customer experience; interactive, virtual, and 3D visualization; distributed cooperative control and scheduling based on Internet technology; intelligent self-learning; and adaptive and distributed learning technologies.

Ubiquitous sensing technology is mainly characterized by intelligent sensor technology and includes intelligent terminal technology and the corresponding operating-system technology. Here, intelligent terminals include intelligent controllers, and industrial sensors such as temperature sensors, humidity sensors, speed sensors, acceleration sensors, and electric eddy current sensors. The ubiquitous sensing technology also includes sensing network management technology, human-computer interaction techniques, and machine-machine interaction techniques, for the industrial Internet, Internet of Things, and wireless sensing networks.

Manufacturing enterprises can build service platforms based on the above modern information technology to realize real-time connection and intelligent interaction between humans, humans and machines, and machines. Different industries need to establish different service platforms for different products, industry links, service content, service modes, and business models.

\subsection{Product design service platform}

The product design service platform can be divided into the personalized design of function or appearance. Functional design can improve product performance, and appearance design can change the structure and appearance of products.

The product design service platform should be based on the Internet and digital design technology, and it should realize remote design and manufacturing in different places through a massive database connected by a distributed R\&D design network. The mass database includes product module, style, performance, process, and other design element information. Remote design and long-distance manufacturing can transform the traditional closed design and production into network collaborative design and production based on virtual network platforms.

\subsection{E-commerce service platform}

The main functions of the e-commerce service platform are electronic procurement of spots and futures, customized trading, 
and online payment services. Spot electronic procurement needs to provide products and inventory, pricing, and negotiation and bidding, and to save the transaction records, track the product delivery schedule, and provide self-help, independent of the bill of lading and other services. The futures electronic procurement service includes providing a product category list, futures order signing, contract process tracking, product distribution management, and other service contents. A custom transaction service can realize the personalized customization of order submission, design proofing, production manufacturing, and logistics delivery. Online payment is provided by a third party, and the instant payment method is made through a bank payment interface, including the transfer and settlement service, and the online credit service has been developed.

\subsection{Remote-monitoring service platform}

The remote-monitoring service platform mainly has two functions: a remote diagnosis service function and a real-time maintenance service function. The company uses high-end intelligent equipment and smart sensors to collect the operational status data of related products and equipment in real time through the network, uses big data storage, analysis technology, and data-mining technology to perform intelligent analysis of running data, implements performance trend and operation fluctuation monitoring, performs fault warning and diagnosis, and carries out regular maintenance, forecast maintenance, failure avoidance, and (automatic) repair work, as well as product or equipment parameter modification and technology upgrading.

\subsection{Supply chain service platform}

The supply chain management service platform should have the following main functions. One is the supply chain inventory management function for downstream businesses and customers, to realize inventory optimization management, reduce inventory cost, and shorten delivery time. The second is the real-time replenishment function, in the face of the downstream enterprises' demand plans, to achieve real-time tracking of supply chain inventory and early warning of the possible shortage of stock. The third is professional logistics service, which provides professional logistics and distribution management services for other enterprises, including optimizing logistics strategic planning, optimizing flow and flow reengineering of logistics networks, and distributing, transporting, and clearing specific products. The fourth is a reverse logistics service, helping other enterprises to manage the return of goods, goods recovery, and reprocessing and disposal of waste goods.

\section{Service strategy requires social support}

The implementation of manufacturing services requires joint efforts of governments, enterprises, and consumers, as well as industry associations, professional associations and societies, institutions of higher learning, and research institutes.

\subsection{Strengthen policy guidance and safeguard a fair market environment}

The government should strengthen the consensus building of manufacturing services, perform annual rolling planning, and monitor and check progress. The government should allow manufacturing enterprises to enter the realm of productive service market permission, simplify examination and approval procedures, provide a comprehensive introduction of competition mechanisms, and resolutely curb acts of unfair competition, avoiding the phenomenon of bad money driving out good. The government should establish an open and transparent market standard system and unified market supervision system. and It should give full play to the supervision of public opinion functions, to crack down on illegal enterprises and their behaviors, expose and discipline producers of fake and shoddy products, and combat rent-seeking behaviors, and it should increase the penalties. The government should advocate the transformation of production and operation modes, enter the high-end segment of the industrial chain, and encourage manufacturing enterprises to provide all-round service content, such as customization, leasing, supply chain maintenance, and engineering integration contracts. The government should promote the outsourcing of enterprise services and encourage the deep integration of manufacturing and producer services.

6.2 Set up a manufacturing service engineering fund to build the manufacturing industry service system

A government-led, voluntary, cofinanced construction of the manufacturing services project fund should be built, and a risksharing mechanism should be implemented.

Advantage should be taken of the manufacturing engineering service fund, actively building up regional service-oriented manufacturing industry parks and service-oriented demonstration bases, to carry out the R\&D of manufacturing service and construction projects and improve the regional manufacturing value chain model of service levels and the construction of manufacturing enterprises, providing collaborative design and manufacturing, mass differentiation customization, business services and supply chain, whole life cycle management, information value-added services, and financing leasing in the field of public services. A professional service, public welfare, and comprehensive manufacturing public information platform should be built to provide the development information of technology related to the global manufacturing and services. Such a platform can provide manufacturing service-related policy, technology, and talent employment counseling, to 
provide data for market demand analysis and provide the relevant professional services, such as finance, insurance, funding, and network training services. Service-oriented manufacturing special activities should be conducted, building an expert database, a knowledge base, a technology database, and a related case base, to develop manufacturing industry parks and key enterprise search, consulting, and diagnostic services, and to carry out manufacturing value chain seminars and training services. Manufacturing enterprises should receive financing to establish an online service platform by implementing such business models as consumer-to-business (C2B) customization, online-to-offline $(\mathrm{O} 2 \mathrm{O})$ mode, and business-to-consumer (B2C) direct selling through applying information technology, such as big data, the Internet, and the Internet of Things. On this platform, such service content as online consulting, online monitoring, and online fault diagnosis should be developed, and simple and decentralized services should be integrated, to form a service pack including requirements analysis, $R \& D$ design, system integration, operation maintenance, and remanufacturing functions, and to promote industry mergers and reorganization between upstream and downstream enterprises, crowdsourcing, and establishment of industry alliances.

\subsection{Create a compound culture and develop the manufacturing service personnel}

Manufacturing enterprises and institutions of higher learning, scientific research institutes, industry associations, and other intermediary organizations should work together to provide targeted training and to look to domestic and foreign institutions of higher learning, scientific research institutes, and other organizations. This training should not only set up manufacturing technology, equipment, and engineering courses; it should also make services technology and management available, to cultivate interdisciplinary development of talent and services more suitable for manufacturing. 